$$
\text { "report" — 2009/6/2 — 23:51 — page } 165 \text { — \#1 }
$$

\title{
Report of Meeting Researches in Didactics of Mathematics and Computer Sciences January 30 - February 1, 2009, Debrecen, Hungary
}

Compiled by K. Lajkó, Gy. MaKsa And Zs. PÁles

\begin{abstract}
The meeting Researches in Didactics of Mathematics and Computer Sciences was held in Debrecen, Hungary from January 30 to February 1, 2009. The 49 Hungarian participants - including $15 \mathrm{PhD}$ students - came from 18 cities and represented 29 institutions of higher education. The abstracts of the talks and the posters and also the list of participants are presented in this report.
\end{abstract}

Key words and phrases: new methods in teaching, experiments in teaching, talent care, history of mathematics and computer sciences.

ZDM Subject Classification: A60.

The meeting Researches in Didactics of Mathematics and Computer Sciences was held in Debrecen, Hungary from January 30 to February 1, 2009 at the clubhouse of the Debrecen Branch of the Hungarian Academy of Sciences. It was organized by the PhD School of Mathematics and Computer Sciences of the University of Debrecen, the Faculty of Informatics of the University of Debrecen, the Kölcsey Ferenc Teacher Training College of the Reformed Church and the Debrecen Branch of the Hungarian Academy of Sciences with the support of the Apáczai Publisher and the Serbonus Kft.

The 49 Hungarian participants - including 15 PhD students - came from 18 cities and represented 29 institutions of higher education.

Copyright (C) 2009 by University of Debrecen 
Professor Gyula Maksa opened the meeting and welcomed the participants to Debrecen. He emphasized that the aim of the meeting is to get to acquainted with each other's results on this field and to offer possibilities for $\mathrm{PhD}$ students to present their works and to know the opinion of the sophisticated colleagues about them.

The 24 scientific talks and 10 posters presented at the meeting focused on the following topics: new methods in teaching, experiments in teaching and reports on the results, talent care, history of mathematics and computer sciences.

The social program - beside the common lunch and dinners - included a reception at the hall of the Kölcsey Ferenc Teacher Training College of the Reformed Church where Professor Zsolt Páles welcomed the participants on behalf of the PhD School of Mathematics and Computer Sciences.

The closing address was given by Professor Károly Lajkó. He recalled that the Didactics Program of the PhD School has been existing just for ten years. During this period 24 successful defences happened. He emphasized the important role of the journal Teaching Mathematics and Computer Science in the $\mathrm{PhD}$ training in this area. He thanked the organizers - especially Eszter Kónya, Herendiné, the staff, the invited lecturers, and the chairs of sections for their efforts and contributions to the success of the meeting. Finally, he announced that the annual organization of this meeting is planned.

Abstracts of the talks and posters follow in alphabetical order and these are followed by a list of participants.

\section{Abstracts of talks}

Ideas, reflections based on the experiences of the Mathematics Didactics $\mathrm{PhD}$ program at University of Debrecen

András Ambrus

Eötvös L. University, Mathematics Teaching and Education Centre, Budapest, Hungary

$$
\text { E-mail: ambrus@cs.elte.hu }
$$

Mihály Csíkszentmihályi a famous American psychologist differentiates three main factors concerning a science domain: 1.The domain of knowledge and actions. 2 The evaluator-circles, who decide the value of the scientific achievement. 3. The contribution of the individual. We analyze the experiences of the Mathematics Didactics PhD Program of University of Debrecen focusing on the three point listed above, special emphasis giving to the development of Didactics of 


$$
\text { "report" — 2009/6/2 — 23:51 — page } 167 \text { — \#3 }
$$

Mathematics as scientific discipline. Finally we formulate some desired changes in the scientific work of Hungarian PhD students.

Use of interactive whiteboard in teaching mathematics

\section{Piroska Biró}

University of Debrecen, Faculty of Informatics, Debrecen, Hungary

E-mail: biro.piroska@inf.unideb.hu

The interactive whiteboard is more and more popular in schools, and the use of it in various classes is getting better and better in Hungary. The interactive whiteboard and the new IT devices infer the appearance of digital school-books, the development of curriculum and the new teaching reform, namely the interactive class (interactive lesson) in the school.

The different types of interactive whiteboards bundled with different types of programs make the educator's work fairly difficult. Even the viewer cannot solve this problem. There are some schools where many types of boards can be found. The new IT devices offer many possibilities for the teachers to present colorful, more interesting and motivating lessons.

In my presentation I am going to show an example of the use of interactive board in a secondary school of Debrecen. I am going to present my research results regarding teaching mathematics using the interactive whiteboard in secondary schools.

Results of an experiment conducted with a high school group. An analysis of series of a certain kind

Károly Csabay

Library of OPSKK, Mezőberény, Hungary

E-mail: csabay@mezobereny.hu

Author gave a lecture for first and second year's visitors of a high school years ago. (Children who heard those presentations were 15-16 years old.) The aim of these lectures was to find some numbers which have got the same sum and product as well. The approach of the solutions was supported by an investigation on the relations between the (natural) number's value and their ciphers. 
Later author has read an article in "Matematika tanítása" (Teaching mathematics - a journal in Hungarian) March, 2008 that deals with sequences $\left(a_{k}\right)$ having the property $\sum_{k=1}^{n} p^{k-1} a_{k}=\prod_{k=1}^{n} a_{k}$ using a certain $p$ that could hold the formal rule of a base of a scale system. Choosing $p=1$ won't plead an actual base but it makes the more simple formula as $\sum_{k=1}^{n} a_{k}=\prod_{k=1}^{n} a_{k}$. Here one can see the $\left(a_{k}\right)$ numbers which satisfy the criterion: their sum equals to their product. After begun with the most simple example $(2+2=2 \times 2)$ author lead his high school team to even so interesting serials as the serial identified by A076628 in the On-Line Encyclopedia of Integer Sequences (also known as Sloane's sequence database and it is to find on the Internet via: http: //www.research.att.com/ njas/sequences).

Author gained the possibility to hold some talks on the same problem to children of the eighth class in the elementary school in Mezőberény, and he could make a comparison between the age 14 against of the high school children aged one or two years older. Author found this age as a sharp border: while high school learners show a special activity in the cooperation and they can reach some yields by a self-supporting way (e.g. the can find numbers 3 and 1.5 where $3+1.5=3 \times 1.5$ independently) on the other hand elementary school children cannot even accept a proof which uses mathematical induction. The age of 14 is an important turning point in the mathematics teaching - this could be a didactical purport of this paper.

Do we need the definition of the properly formatted text?

\section{Mária Csernoch}

University of Debrecen, Kossuth L. Teacher Training High School, Debrecen, Hungary

E-mail: mariacsernoch@hotmail.com

It is experienced that most of the texts created by word processors, especially with Word, are loaded with unexpected mistakes originating from the improper usage of these programs. The question is why these so popular applications are used so inappropriately? Analyzing these documents revealed that even today there are no set rules of a properly formatted text. As a consequence many users have no clear understanding whether the formatting they apply is correct or not. By categorizing the typical mistakes found I was able to collect a set of maxims which can serve as the definition of the properly formatted text. Those 


$$
\text { "report" — 2009/6/2 — 23:51 — page } 169 \text { — \#5 }
$$

users, who are familiar with this definition and willing to apply it, would create correctly formatted texts. The final goal, however, beyond finding this definition, is to make it widely known and applied. To reach this the definition has to be accepted and widely spread by teachers of Informatics.

\author{
Numbers in Grade1 in an IB school \\ Aranka Engbersen \\ Vienna International School, Vienna, Austria \\ E-mail: engbersen@hotmail.com
}

The today's extent of the late Middle Ages started globalization surely changes our ways of thinking. In the sixties founded International Baccalaureate Organization (IBO) offers high quality program for schools and students taking part in international education.

In my presentation I introduce the structure of IBO, its primary years mathematics program and the beginnings of my works in the field of numbers in Vienna International School.

The formation of geometrical terms

\author{
Katalin Földesi \\ Mälardalens Högskola, Sweden \\ E-mail: katalin.foldesi@mdh.se
}

It was almost two years ago that I, in the context of a geometry course that nearly ended in scandal, arrived with the help of my supervisor at the theme of my research: the formation of geometrical terms.

When researching about how to teach geometry, people often refer to P. van Hiele. Influenced by his own geometry teaching and an exceptionally inspiring professional environment, a few decades ago the Dutch researcher P. van Hiele worked out a way to classify levels of geometrical thinking. A few years after these levels became widespread, Z. Usishkin published in 1982 a test, which could be used to determine the level of geometrical thinking of a student. After the brief introduction of this test, I would like to sum up some related research results, after which I shall present the plan for my own research. 


$$
\text { "report" — 2009/6/2 — 23:51 — page } 170 \text { — \#6 }
$$

Occurrence of using the direct translation strategy between Hungarian primary and secondary school students

\section{István Gubo}

J. Selye University, Faculty of Pedagogy, Department of Computer Sciences,

Komárno, Slovak Republic

E-mail: guboi@selyeuni.sk

The main purpose of this presentation is to introduce the results of an empirical research which was conducted at Primary (Grade 5 and 8) and Secondary (Grade 10) schools in Hungary. The foremost aim of this research was to examine students' written performance in solving non-routine word problems.

MAYER and HEGARTY distinguished between two general approaches to solving word problems, which they labelled the direct translation strategy and the problem model strategy. In the direct translation strategy, problem solver begins by selecting numbers and keywords from the problem and preparing to perform arithmetic operations on them. According to the authors students who have worse school results in mathematics are more likely than students with greater mathematical knowledge to use the direct translation strategy. Successful students are able to construct a wider mental representation of the situation. When they are confronted with a mathematical word problem, they begin by trying to understand the situation being described in the problem and devising a solution plan based on their representation of the situation.

We will present the quantitative analysis of three word problems used in the study (water lilies, meeting-up and socks). Furthermore, we will also provide examples of wrong answers most frequently given by students and some explanations to our findings.

Some remarks on teaching of mathematics

\section{Jenő Horváth}

West-Hungarian University, Faculty of Forestry, Institute of Mathematics, Sopron, Hungary

E-mail: jhorvath@emk.nyme.hu

Our experience is that the students beginning theirs studies at universities or colleges know the mathematics (not only the mathematics) less and less. The universities have to give prelectures grounding the usual lectures in mathematics. 


$$
\text { "report" — 2009/6/2 — 23:51 — page } 171-\# 7
$$

The question is that we resign ourself to this situation or we can something to do.

In the first part of the lecture we deal with some "new" theorems and "interesting" solutions of exercises which are given by students. The lecturer give the broad outlines of the reasons. Finally he sketches his ideas for the change of the present situation.

Mathematics Teaching Improvement with help of the Method Professional Development of Teacher-Researchers

Tünde Kántor - András Kovács

University of Debrecen, Institute of Mathematics, Debrecen, Hungary

E-mail: tkantor@math.klte.hu, kovacsa@math.klte.hu

The aim of the Krygowska project has been to engage classroom teachers of mathematics in the process of systematic, research-based transformation of their classroom practice. The PISA results have shown that the teaching of mathematics is in crisis. It became evident that there is a need for a deep change in the teaching methods of mathematics. The new pedagogical method, the teaching research method, developed by Bronislaw Czarnocha at New York City University seemed to be a good solution.

Six selected teams of teachers from 5 countries (Hungary, Italy, Poland, Portugal, and Spain) have been invited to participate in the Krygowska Project. From Hungary one team took part in this project. The coordinator institute was the Department of Mathematics of the University of Debrecen. In Hungary there were traditions of the TR method because Tamás Varga applied it.

In this presentation

- we analyse the definition of Teacher Researcher (TR)

- we present our research work done during the three years 2006-2008

- we analyse our main tasks and our results

- we present our contributions to the TR conferences (Debrecen, Barcelona, Siedlice).

- In the poster section we present 8 posters made by Hungarian teachers and their mentors. 


$$
\text { "report" — 2009/6/2 — 23:51 — page } 172 \text { — \#8 }
$$

(Krygowska Project for Professional Development of Teacher-Researchers, no. 226685-CP-1-2005-1-PL-Comenius-C21, Socrates Program of the European Comission)

\section{The Measuring of the Computer Science Education in Hungary}

\section{Gábor Kiss}

Budapest Tech Polytechnical Institution, Budapest, Hungary

E-mail: kiss.gabor@bgk.bmf .hu

I have made a test to compare the German and the Hungarian Computer Science Education.

The basic idea is to prepare a web-based on-line questionnaire with several test questions for students from all regions and all grades in Germany and in Hungary.

The answers will help to show how the two education systems differ from each other. In order to reach the best results the author used unified questions of computer science based on the national/regional curricula of Hungary and Germany.

Students can tick some of the themes (except for basic computer science and office packages, because these themes appear in both countries in every region) by the fill of test, which they have never learned. In this case the system does not ask questions in connection with those topics but registers and saves them as the answer, "I've never come across that".

This test has filled 1564 students in Hungary and I have made a valuation, in which I have analyzed how the students answered the questions of the parts of Computer Science Education. By the analysis can see which parts are too complicated for the students. Which parts have they learned, or not. The answers can show in the school the students learned some parts one, two years later, than it is described in National Basic Curriculum. 


$$
\text { "report" — 2009/6/2 — 23:51 — page } 173 \text { — \#9 }
$$

On college students' habits in learning mathematics, in connection with a questionnaire survey

István Molnár

Szent István University, Faculty of Economics, Békéscsaba, Hungary

E-mail: molnar@zeus.tsf.hu

In my presentation I go through the more interesting findings of a questionnaire survey done among college students. The purpose of the survey was to highlight and bring to surface the problems and difficulties that arise in teaching the Economic Mathematics I course, and to get to know the students' learning habits. The target group was the first-year full-time students at the TSF Faculty of Economics.

In the first part of the presentation I analyse the connection between the mathematics marks of school-leaving exams and the marks of the Economic Mathematics I course taught in the first semester. In the second part I talk about the time spent on studying mathematics, the students' learning habits, and their motivations for learning. Finally I show what areas cause them the most trouble in learning mathematics, and what ideas they have to improve the teaching of the subject.

In computational practices occurring problems and their possible solution

\author{
Csilla Muhari \\ Dennis Gabor Applied University, Budapest, Hungary \\ E-mail: muhari@gdf .hu
}

In my presentation I would like to call the attention for an often appearing problem, which every teacher confronts daily, weekly, if considers computerised practice to students with different preparedness. Another didactics solution is expected from the instructor, another contact evolves between the instructor and the students, than with the occasion of the seminar lectures. The practices demand the students' active participation, even in the form of individual work, even with an answer to the teacher's question. I propose the smooth solution of the emerging problems on the one hand technical, on the other hand from a didactics viewpoint. 


$$
\text { "report" — 2009/6/2 — 23:51 — page } 174-\# 10
$$

\author{
Calculus, discretely \\ Zsolt Páles \\ University of Debrecen, Institute of Mathematics, Debrecen, Hungary \\ E-mail: pales@math.klte.hu
}

The discrete analogues of differentiation and integration, the difference sequences, and partial sums of sequences are investigated. The formulae that correspond to the Newton-Leibniz formula and partial integration are established. As application, formulae for partial sums in various classes of sequences are derived.

The development of the high school application of linear optimisation

\title{
Ildikó Patak \\ Gábor Á. High School, Karcag, Hungary \\ E-mail: i.patak@freemail.hu
}

My lecture is about the discussion of linear optimisation in high schools. I show how they imagined the discussion of this topic in the past, in Hungary and abroad, and how we would teach it nowadays. I explain why this point in mathematics can be interesting, as well as what difficulties can occur during its teaching.

Practice oriented school-leaving examination of mathematics in the

\section{EU-States}

Tiborné Petz

West-Hungarian University, Apáczai Faculty, Győr, Hungary

E-mail: toth.szilvia@atif.hu

The subject of my talk is the short presentation of my doctoral/PhD dissertation. In the course of this I compare mathematics school-leaving exams in the EU-States. After that I examine the connection between contents and reality. I am searching answers of questions, as for example: in which country, how much can people make good use of mathematics knowledge and how students can recognize the material of lessons in everyday life. 


$$
\text { "report" — 2009/6/2 — 23:51 — page } 175 \text { — \#11 }
$$

Examination of the factors influencing the exam results of the subject Introduction to Informatics

Cecilia Görömbei, Sitkuné

College of Nyíregyháza, Nyíregyháza, Hungary

E-mail: sitkune@nyf.hu

The defectiveness of the effectiveness of the Hungarian general education revealed in the PISA survey appears in the higher education as well. The Introduction to Informatics subject has one of the lowest exam results among the students of the College of Nyíregyháza majoring in Computer Programmer Mathematician and Computer Program Designer (hereafter CPM/CPD) and Teacher of Computer Science (hereafter TCS). This subject is the mediator subject for the elements of informatics for the students. By analysing the results of supplementary surveys I try to find answers for the following questions:

What are the relations between the exam results of the students and the secondary final examinations that should measure their previous knowledge? Can the weak results be explained by the thinking ability or rather the defectiveness of the special mathematics skills? What are the students' motivation and attributions towards the exam results?

In the years 2005/2006 and 2006/2007 I made a measuring among the TCS and CPM/CPD students by using the test sheet used in the previous year. I also made supplementary measures (inductive thinking test, basic calculation skill test, attribution questionnaire) among the TCS students.

I compared the results of the CPD students with the results of the CPM students.

Taking into consideration the average of the school leaving exam we can draw the conclusion that exam results are much the weak than the average of the secondary school leaving exam.

In the case of the TCS students I examined relation between the exam results and the supplementary survey results.

Test of inductive thinking: The college students performed worse than the 11th year students in the test of number and word analogy and performed a little better in the test of sequence of numbers.

Test of basic counting skill: The students managed to achieve the level of the grown-up intellectuals only at the extraction part test but performed worse than the 8 th year primary school students at the multiplication test. 


$$
\text { "report" — 2009/6/2 — 23:51 — page } 176 \text { — \#12 }
$$

Attribution questionnaire: It can be said that the students admitted their own responsibility in their exam results but their attitude towards values is affected to a great extent by the changing of the attitude towards values experienced nowadays.

The results of the investigations and surveys done show that most of the students come to higher education with a weak fundamental knowledge. In order to improve the results of the exams the individual improvement of those students who perform badly in the given fields is required.

\section{Integrated education for blind children: the acustic representation of function's properties \\ Szilvia Nagy, Szakácsné \\ Szent István University, Faculty of Economics, Békéscsaba, Hungary \\ E-mail: szilvi@zeus.tsf.hu}

We analyse the development opportunities of function's properties studies with the help of sonification. Sonification of graphs has been the subject of several interesting research projects over the years (Mansur-1975; Kennel-1996). Abroad nowadays several accessible interfaces exist that allows visually impaired users to browse graphical information using tactile and audio feedback. Unfortunately these are not yet available in the Hungarian language. For our analysis we use the MathTrax software developed by NASA in 2006. The MathTrax is a graphing tool for middle school students to graph equations, it gives the graphs descriptions and sound, so we can hear and read about the graph. Useing MathTrax sounds of graphs blind students may study several properties of functions (increase and decrease; continuity, periodicity, limited functions etc.).

\section{The Tree of Science}

\section{Julianna Szendrei}

Eötvös L. University, Faculty of Elementary and Nursery School Teachers'

Training, Budapest, Hungary

E-mail: szendrei.julianna@elte.tofk.hu

The headline of this lecture is a reference to the book, written by Ramon Llull in the 13 th century, the purpose of which was the understanding of sciences. The 


$$
\text { "report" — 2009/6/2 — 23:51 — page } 177 \text { — \#13 }
$$

formation of the didactic program of mathematical graduate school of Debrecen started at a discussion at a conference and came eventually to as the result of the selfless work of many mathematicians and teachers. "This is the most school-like of schools" - said the lecturer - "as here the Ph.D. students can run into dead ends as well as detours". What is needed for good research? The passionate interest of the researcher being familiar with the work of his peers, the milieu and even the knowledge of the social medium. And Masters, whose selfless, informal assistance is a great driving force. What is worth researching? Is mathematical didactics a science? What is the role of an individual in research? Why does a good teacher need research? Research or development? What kind of cooperation is necessary in mathematical didactic research? What is good research? The lecture using several examples helped answering these important questions.

\section{Aufbau und Sortierung von Rechtecken in der 4. Klasse \\ Ibolya Szinger, Szilágyiné \\ Eötvös J. College, Baja, Hungary \\ E-mail: szilagyine.szinger.ibolya@ejf.hu}

Während eines Lehrexperiments haben wir in der 4. Klasse die Entwicklung einiger geometrischen Begriffe $u$. a. die des Rechteckes untersucht. In dieser Vorlesung präsentieren wir Aufgaben in Zusammenhang mit Aufbau und Sortierung von Rechtecken, weiterhin beschäftigen wir uns mit einigen typischen Problemen, Denkfehlern. Erkennen die Schüler in der 4. Klasse, dass das Quadrat ein Rechteck ist oder noch nicht? Auch auf diese Frage suchen wir die Antwort.

Speciality of probabilistic thinking

\section{Judit Szitányi}

Eötvös L. University, Faculty of Elementary and Nursery School Teachers'

Training, Budapest, Hungary

E-mail: szitanyi.judit@gmail.com

The basic ambition of the modern school is to supply pupils with well applicable knowledge in their daily life. Practical advantages of the probability theory are not questionable due to we often make probability decisions in our daily and 


$$
\text { "report" — 2009/6/2 — 23:51 — page } 178 \text { — \#14 }
$$

scientific life. In my investigation, I'm looking for the answers how the probability decisions and estimations can be differentiated from the thinking strategies applied on other areas of mathematics. I also investigate that how deeply the probability studies are integrated into the high-school graduated students' thinking. I discuss it in my presentation by showing up the results of a measurement filled up by teacher candidates and the experiences of recorded lessons in a semester.

Applications of the orthogonal projection

Ágota H. Temesvári

West-Hungarian University, Faculty of Forestry, Institute of Mathematics, Sopron, Hungary

E-mail: hta@emk.nyme.hu

The orthogonal projection is a very useful method for solving of geometric problems. In the present lecture we give some examples from the secondary school. The orthogonal projection is one of the important tools in descriptive geometry. The proper preparing in the secondary school would be useful in solving problem in stereometry, in description of spatial figures and development of the ability to orient in the space.

\author{
Abstracts of posters \\ The experience of mathematics \\ Éva Balla \\ Hőgyes Endre High School, Hajdúszoboszló, Hungary \\ E-mail: balle@freemail.hu
}

Surveys show that the learning motives decrease strongly in the course of the years spent in school. The lower level of learning efficiency is the obvious consequence of the decreasing motivation. In my work I summarized the experiences of some teaching experiments, which aim was to increase students' interest and activity. 


$$
\text { "report" — 2009/6/2 — 23:51 — page } 179-\# 15
$$

Researches in Didactics of Mathematics and Computer Sciences

Motivating low ability students in Maths lessons

\section{Krisztina Barczi}

University of Debrecen, Kossuth Lajos Teacher Training High School, Debrecen, Hungary

E-mail: madmedve@citromail.hu

The motivation level of low ability students in Maths lessons is usually not very high. Is there a way to make these lessons more interesting for them? Can we make them want to participate more? In this investigation I tried to answer these questions with the help of my students. My work is a summary of the changes that were introduced in class and the effect of these changes on the attitude of my students towards learning Maths.

\section{Egyptian fractions in teaching}

Béla Kallós

Szent Imre Catholic High School, Nyíregyháza, Hungary

E-mail: kallosbela@gmail.com

This poster introduces a few opportunities to use Egyptian fractions in the teaching of fractions in the 5th and 6th classes. An Egyptian fraction is a unit fraction (where the numerator is 1 ) or a sum of unit fractions. This concept can be useful in the teaching of fractions (e.g. comparing fractions, connecting between multiplication and division, etc.). The main part of poster contains some interesting tasks and the students' solutions which I used in my lessons. Otherwise, I am going to demonstrate the teaching of fractions in Hungarian schools from the 1st class to the 6 th class. In addition we can get acquainted with a historical (the Rhind Mathematical Papyrus) and a linguistic (the difference between the "half" and the "two" words in a few languages) curiosity. My experience showed that students' motivation may rise in classroom because of knowing Egyptian fractions. 


$$
\text { "report" — 2009/6/2 — 23:51 — page } 180-\# 16
$$

Solution of an extremal problem with the method of cooperative learning

$$
\text { Tünde Kántor - András Kovács }
$$

University of Debrecen, Institute of Mathematics, Debrecen, Hungary

E-mail: tkantor@math.klte.hu, kovacsa@math.klte.hu

The following problem was posed to the students: A farmer has an adjustable electric fence that is $120 \mathrm{~m}$ long. He uses this fence to enclose a rectangular grazing area. Find the maximum area he can close.

We investigated how could the students in class 9-th solve this problem with the method of cooperative learning.

Our expected solutions were:

- Systematic trials

- Using characteristics of the quadratic functions ( algebraic and graphical methods)

- Geometrical methods

The members of the groups discussed together the problem each group could solve it in some kind of way and could tell it to the others at the blackboard.

\section{Problem solving with Dynamic Geometry System}

Rita Kondor, Nagyné

University of Debrecen, Debrecen, Hungary

E-mail: kondorri@freemail.hu

As regards construction with dynamic geometry system (DGS), as well as traditional constructions and the preparation of static figures, we can shift the fundamentals of the construction at will. The figure being drawn thereby changes consistently, since the program views the figure as a dynamic whole. Moreover, these systems can store the construction steps and execute them after modification of the input data. According to our experience so far we can say that DGS helps the teaching of the descriptive geometry and it is also a useful help to improve the students outlook in geometry. We can improve the student's problem-solving abilities with the help of the interactive work-sheets and improvement in the field of creativity was observed among the students. 


$$
\text { "report" — 2009/6/2 — 23:51 — page } 181 \text { — \#17 }
$$

Researches in Didactics of Mathematics and Computer Sciences

PISA-like Problems solved by students with high abilities

Anna Fazekas, Kozárné

University of Debrecen, Kossuth Lajos Teacher Training High School, Debrecen, Hungary

E-mail: kozarne.fanna@t-online.hu

In this poster I am going to show the results of my research carried out at Kossuth Lajos Teacher Training Secondary Grammar School of Debrecen University, which is one of the best schools in Hungary. Two groups of students aged 15 were tested on two PISA problems modified: 'Apples' and 'Carpenter'. These problems were modified in order to make them more challenging for students. With this research I was trying to uncover some possible reasons for student's low achievement at PISA tests.

\section{Biomathematics}

Ildikó Patak

Gábor Áron High School, Karcag, Hungary

E-mail: i.patak@freemail.hu

We did a teaching experiment on the search for real world problems connected with the data of our National Parks. Our problems concerned with flowers, with birds and animals. We chose the method of cooperative learning for discussing these problems connected with biology.

\section{Mathematics and Game \\ István Takács \\ Katona József High School, Kecskemét, Hungary \\ E-mail: itakacs@kjg.hu}

The Hungarian mathematics teaching in secondary grades is rather formal, abstract. The science mathematics is the main factor to influence this approach. To change this I started to play with the children. During the game we could find the core of knowledge. That poster is created for students to see the meaning of rotations. 


$$
\text { "report" — 2009/6/2 — 23:51 — page } 182 \text { — \#18 }
$$

How to move an elephant?

Mariann Tóth

Fazekas Mihály High School, Debrecen, Hungary

E-mail: t4242m@gmail.com

Teaching isometrics can raise several problems. Some of them can be solved by using tracing-paper before construction exercises

- The first aim of tracing- paper exercises was to surmount students' lack of construction skills.

- The second aim was to show them many examples how isometrics work in order to develop the idea that isometrics move all points of the plane not just the highlighted ones.

Teaching and learning basic algorithms by the help of algorithm-visualization tools

Gábor Törley

Corvinus University of Budapest, Faculty of Public Administration, Hungary

E-mail: gabor.torley@uni-corvinus.hu

The presentation aims at illustrating how the algorithm-visualization tools can be used both by the teacher and the pupil, especially during the teaching and learning of basic algorithms. The presentation will evaluate the teaching and learning method as well.

According to my experiences, the hardest part of learning basic algorithms is - as a teacher and as a pupil - when we are searching for an answer to the question: Why that given algorithm will be correct, why will it solve our problem? Evidently, we have to reject verification as an answering tool as in secondary school the pupils do not have the necessary knowledge; moreover, it would rather scare them. Another reason for ignoring clear mathematical tools is that the goal of programming would be that the pupils' cognitive skills are developed.

I have concluded from my earliest experiences that if I use tools during teaching which help to imagine what is happening inside the algorithm, the process of understanding will be faster. The use of algorithm-visualization (AV) tools provides solution for this. I show two examples for AV environment: Jeliot 3, which was developed by researchers from the University of Joensuu, Finland and 


$$
\text { "report" — 2009/6/2 — 23:51 — page } 183 \text { — \#19 }
$$

TRAKLA2, which was created by the specialists of the Technical University of Helsinki, Finland.

\section{List of participants}

1) András Ambrus, Eötvös L. University, Mathematics Teaching and Education Centre, Budapest, Hungary, ambrus@cs.elte.hu

2) Éva Balla, Hőgyes Endre High School, Hajdúszoboszló, Hungary, balle@freemail.hu

3) Tünde Baranyai, Babes Bolyai University, Faculty of Psychology and Educational Sciences, Szatmárnémeti, Romania, baratun@yahoo.com

4) Krisztina Barczi, University of Debrecen, Kossuth L. Teacher Training High School, Debrecen, Hungary, madmedve@citromail.hu

5) Piroska Biró, University of Debrecen, Faculty of Informatics, Debrecen, Hungary, biropiroska@yahoo.com

6) Károly Csabay, Library of OPSSK, Mezőberény, Hungary, csabayk@yahoo.com

7) Ildikó Vecsei, Cserhátiné, Kölcsey F. Teacher Training College of the Reformed Church, Debrecen, Hungary, vecsei@kfrtkf .hu

8) Mária Csernoch, University of Debrecen, Kossuth L. Teacher Training High School, Debrecen, Hungary, csernochm@klte-gyakorlo.sulinet.hu

9) Géza Csóka, West-Hungarian University, Apáczai Faculty, Győr, Hungary, csoka@atif.hu

10) József Daragó, Kölcsey F. Teacher Training College of the Reformed Church, Debrecen, Hungary, darago@kfrtkf .hu

11) Edit Debrenti, Nagyvárad, Románia, debrenti_edit@kdslink.ro

12) Aranka Engbersen, Vienna International School, Vienna, Austria, engbersen@hotmail.com

13) Katalin Földesi, Mälardalens Högskola, Sweden, katalin.foldesi@mdh.se

14) István Gubo, J. Selye University, Faculty of Pedagogy, Komárno, Slovak Republic, guboi@selyeuni.sk

15) Eszter Kónya, Herendiné, Kölcsey F. Teacher Training College of the Reformed Church, Debrecen, Hungary, hke@kfrtkf .hu 


$$
\text { "report" — 2009/6/2 — 23:51 — page } 184 \text { — \#20 }
$$

16) Jenő Horváth, West-Hungarian University, Faculty of Forestry, Institute of Mathematics, Sopron, Hungary, jhorvath@emk.nyme.hu

17) Béla Kallós, Szent Imre Catholic High School, Nyíregyháza, Hungary, kallosbela@gmail.com

18) Sándor Kántor, University of Debrecen, Institute of Mathematics, Debrecen, Hungary, kantors@math.klte.hu

19) Tünde Kántor, University of Debrecen, Institute of Mathematics, Debrecen, Hungary, tkantor@math.klte.hu

20) Gábor Kiss, Budapest Tech Polytechnical Institution, Budapest, Hungary, kiss.gabor@bgk. bmf .hu

21) Éva Kopasz, Eötvös J. College, Baja, Hungary, kopasz. eva@ejf.hu

22) András Kovács, University of Debrecen, Institute of Mathematics, Debrecen, Hungary, kovacsa@math.klte.hu

23) Ildikó Székely, Kozákné, József A. High School, Monor, Hungary, kiszekely@yahoo.com

24) Anna Fazekas, Kozárné, University of Debrecen, Kossuth L. Teacher Training High School, Debrecen, Hungary, kozarne.fanna@t-online.hu

25) Péter Körtesi, University of Miskolc, Miskolc, Hungary, pkortesi@gmail.com

26) Károly Lajkó, University of Debrecen, Institute of Mathematics, Debrecen, Hungary, lajko@math.klte.hu

27) Gyula Maksa, University of Debrecen, Institute of Mathematics, Debrecen, Hungary, maksa@math.klte.hu

28) István Molnár, Szent István University, Faculty of Economics, Békéscsaba, Hungary, molnar@zeus.tsf .hu

29) Csilla Muhari, Dennis Gabor Applied University, Budapest, Hungary, muhari@gdf.hu

30) Katalin Munkácsy, Eötvös L. University, Mathematics Teaching and Education Centre, Budapest, Hungary, katalin.munkacsy@gmail.com

31) Rita Kondor, Nagyné, University of Debrecen Faculty of Engineering, Debrecen, Hungary, kondorri@freemail.hu

32) Zsolt Páles, University of Debrecen, Institute of Mathematics, Debrecen, Hungary, pales@math.klte.hu 


$$
\text { "report" — 2009/6/2 - 23:51 — page } 185-\# 21
$$

33) Katalin Varga, Pásztorné, Eötvös L. University, Mathematics Teaching and Education Centre, Budapest, Hungary, pkata@ludens.elte.hu

34) Ildikó Mária Patak, Gábor Áron High School, Karcag, Hungary, ipatak@gaboraron-karcag.sulinet.hu

35) Tiborné Petz, West-Hungarian University, Apáczai Faculty, Győr, Hungary, toth_sz@atif.hu

36) Cecília Görömbei, Sitkuné, College of Nyíregyháza, Nyíregyháza, Hungary, sitkune@zeus.nyf .hu

37) Szilvia Nagy, Szakácsné, Szent István University, Faculty of Economics, Békéscsaba, Hungary, szilvi.nagy.sz@citromail.hu

38) Gábor Szalontai, szalontai.gabor@gmail.com

39) Tibor Szalontai, College of Nyíregyháza, Nyíregyháza, Hungary, szalonta@nyf.hu

40) Julianna Szendrei, Eötvös L. University, Faculty of Elementary and Nursery School Teachers' Training, Budapest, Hungary, szendrei.julianna@elte.tofk.hu

41) Ibolya Szinger, Szilágyiné, Eötvös J. College, Baja, Hungary, szilagyine.szinger.ibolya@ejf.hu

42) Judit Szitanyi, Eötvös L. University, Mathematics Teaching and Education Centre, Budapest, Hungary, szitanyi.judit@gmail.com

43) István Takács, Katona József High School, Kecskemét, Hungary, itakacs@kjg.hu

44) Margit Tarcsi, Kölcsey F. Teacher Training College of the Reformed Church, Debrecen, Hungary, tarcsimarcsi2@t-online.hu

45) Ágota Temesvári, West-Hungarian University, Faculty of Forestry, Institute of Mathematics, Sopron, Hungary, hta@emk.nyme.hu

46) Mariann Tóth, Fazekas M. High School, Debrecen, Hungary, t4242m@gmail.com

47) Gábor Törley, Corvinus University of Budapest, Faculty of Public Administration, Budapest, Hungary, gabor .torley@uni-corvinus.hu

48) Csaba Vágvölgyi, Kölcsey F. Teacher Training College of the Reformed Church, Debrecen, Hungary, vagvolgy@kfrtkf .hu

49) Magda Várterész, University of Debrecen, Faculty of Informatics, Debrecen, Hungary, varteresz.magda@inf .unideb.hu 


$$
\text { "report" — 2009/6/2 — 23:51 — page } 186 \text { — \#22 }
$$

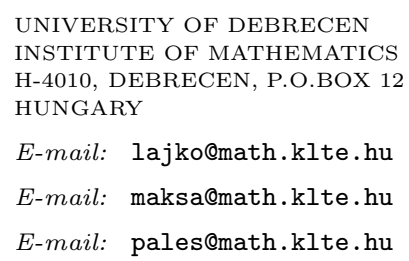

(Received April, 2009) 